\title{
Basal Diet
}

National Cancer Institute

\section{Source}

National Cancer Institute. Basal Diet. NCI Thesaurus. Code C90364.

The fundamental nutritional components that constitute an organism's daily intake of foodstuffs. 